\title{
Influence of Female Sex Hormones on Ultra-Running Performance and Post-Race Recovery: Role of Testosterone
}

\author{
Eladio Collado-Boira ${ }^{1, *,+} \oplus$, Pablo Baliño ${ }^{1, *, \dagger}$, Ana Boldo-Roda ${ }^{2}$, Ignacio Martínez-Navarro ${ }^{3,4} \mathbb{D}$, \\ Bárbara Hernando ${ }^{1}$, Paula Recacha-Ponce ${ }^{1} \mathbb{D}$, Carlos Hernando ${ }^{5,6} \mathbb{\mathbb { D }}$ and María Muriach ${ }^{1}$ \\ 1 Faculty of Health Sciences, Jaume I University, 12071 Castellon, Spain; hernandb@uji.es (B.H.); \\ recacha@uji.es (P.R.-P.); muriach@uji.es (M.M.) \\ 2 Obstetrics and Gynecology, University Hospital of La Plana, 12540 Vila-Real, Spain; anaboldoroda@gmail.com \\ 3 Department of Physical Education and Sport, University of Valencia, 46010 Valencia, Spain; \\ ignacio.martinez-navarro@uv.es \\ 4 Sports Health Unit, Vithas-Nisa 9 de Octubre Hospital, 46015 Valencia, Spain \\ 5 Sport Service, Jaume I University, 12071 Castellon, Spain; hernando@uji.es \\ 6 Department of Education and Specific Didactics, Sport Service, Jaume I University, 12071 Castellon, Spain \\ * Correspondence: colladoe@uji.es (E.C.-B.); balino@uji.es (P.B.) \\ + These authors contributed equally to this work.
}

Citation: Collado-Boira, E.; Baliño, P.; Boldo-Roda, A.; Martínez-Navarro, I.; Hernando, B.; Recacha-Ponce, P.; Hernando, C.; Muriach, M. Influence of Female Sex Hormones on Ultra-Running Performance and Post-Race Recovery: Role of Testosterone. Int. J. Environ. Res. Public Health 2021, 18, 10403. https:// doi.org/10.3390/ijerph181910403

Academic Editors: Stacy T. Sims and Christopher T. Minson

Received: 24 July 2021

Accepted: 28 September 2021

Published: 2 October 2021

Publisher's Note: MDPI stays neutra with regard to jurisdictional claims in published maps and institutional affiliations.

Copyright: (c) 2021 by the authors. Licensee MDPI, Basel, Switzerland. This article is an open access article distributed under the terms and conditions of the Creative Commons Attribution (CC BY) license (https:// creativecommons.org/licenses/by/ $4.0 /)$

\begin{abstract}
In recent years, increasing numbers of women have participated in extremely long races. In adult males, there is a clear association between physiological levels of endogenous sex hormones and physical performance. However, the influence of plasmatic sex hormones and the effects of different types of hormonal contraception (HC) on the modulation of physical performance in adult females remain to be fully clarified. Eighteen female ultra-endurance athletes were recruited to participate in the study. Different variables were studied, including hematological parameters, body mass index, and body composition. Strength measurements were obtained using the squat-jump and hand-grip test. A repeated-measures analysis demonstrated significant differences in hematological values of CK and LDH pre-race as compared to immediately post-race and after $24 / 48 \mathrm{~h}$. Furthermore, statistical differences were found in squat-jump and hand-grip test results after the ultramarathon. Testosterone, estradiol, and the testosterone/estrogen ratio were significantly correlated with muscle fatigue and were found to be indirect markers of muscle damage. A multivariate analysis demonstrated the protective role of testosterone against muscle damage and severe fatigue. Fluctuations in endogenous testosterone levels were correlated with greater fatigability and muscle damage after the competition. Adjusting the menstrual cycle with HC would not provide any further benefit to the athlete's competitive capacity.
\end{abstract}

Keywords: ultra-endurance; hormones; female athletes; physical performance; muscle damage; muscle fatigue; hormonal contraception

\section{Introduction}

Ultramarathon races are defined as sporting events that involve running and/or walking for distances greater than the official marathon distance of $42.195 \mathrm{~km}$. In recent years, these competitive events have increased in popularity [1]. These extremely long races defy our physiological systems, inducing muscle injuries, respiratory fatigue, and cardiac and renal damage. They, thus, provide an outstanding model to evaluate the effects of ultraendurance activities on the human body. The percentage of women participating in ultraendurance sports has greatly increased in recent years [2]. In elite athletic competitions, males and females are usually separated, thus avoiding disadvantages for females in terms of strength, power, and speed as compared to their male counterparts.

It has been demonstrated that sex differences in sports performance are associated with higher circulating testosterone concentrations in males during puberty. In fact, results from 
sports competitions show no sex differences prior to puberty. Postpubertal testosteroneinduced changes occur with regard to muscle mass, strength, bone composition, and hemoglobin levels, conferring a physical advantage in sporting events [3].

Male sex hormones such as testosterone, dihydrotestosterone, and dehydroepiandrosterone modulate the different physiological mechanisms that are responsible for athletic performance improvement $[4,5]$. Testosterone binding to the androgen receptor at the surface of the muscle fiber increases calcium release from the intracellular stores, activating different mechanisms that increase the number of muscle fibers and satellite cells, as well as the size of motor neurons [6]. Thus, skeletal muscular activity is enhanced, eliciting improved athlete performance and recovery [7].

Although there is a clear association between physiological levels of endogenous testosterone and physical performance in men $[3,8]$, the influence of plasma concentrations of female androgens on sports performance needs to be clarified. The paucity of research on female athletes can be attributed to the cultural marginalization of women in sport and a lack of female participation in both the research and sporting contexts [9]. It is also the result of the cofounding variables of female sex hormone fluctuations, for example in terms of the endogenous hormone profile and differences in this profile under the use of hormonal contraception [10]. Further, the greater incidence of anovulation and luteal phase deficiency in female athletes complicates research in this regard [11].

Athletic amenorrhea is common in elite female athletes. It has been postulated to be an adaptative mechanism to a negative energy balance (hypometabolic state), and is associated with low testosterone levels [12]. Conversely, Hagmar [13] reported that most cases of menstrual disturbances observed among female elite athletes were due to polycystic ovary syndrome (PCOS). Interestingly, this syndrome is characterized by an elevated ovarian production of testosterone and is associated with greater muscle mass [14,15]. This increase in testosterone levels may positively modulate physical performance in athletes, especially in ultra-endurance events.

Estrogen is thought to be another hormonal factor modulating muscle strength, metabolism, and stiffness [16]. Moreover, the testosterone/estrogen ratio ( $\mathrm{T} / \mathrm{E}$ ratio) has been recently considered as a predictor of over-training syndrome in male athletes [17]. Hence, basal estrogen levels and the testosterone/estrogen ratio (T/E) are critical to a better understanding of ultra-trail performance and post-race recovery in female runners.

It has been reported that many elite female athletes use hormonal contraception, with figures varying from $20 \%$ to $70 \%$ depending on the country and sport [18-21]. However, little is known about the impact and prevalence of $\mathrm{HC}$ use and the effects of intermittent treatment. Furthermore, the physiological aspects of $\mathrm{HC}$ use are not always considered when monitoring the health of athletes.

As such, we hypothesized that the menstrual cycle phase and, in particular, its influence on testosterone levels could modulate muscular physiological response and recovery after intense sporting activity in ultra-trail events. Thus, we aimed to elucidate the influence of basal testosterone and the T/E ratio on the post-race loss of skeletal muscle strength and muscle damage in female ultra-trail runners. The objectives of this study were extended to consider whether $\mathrm{HC}$ could influence these variables.

\section{Materials and Methods}

\subsection{Study Design}

This was a cross-sectional observational study that formed part of the Penyagolosa Trail Healthy Women project and involved a sample of 18 amateur runners who participated in the Penyagolosa Trail CSP ultra-trail race on 12 May 2018. The trail track was of $107.4 \mathrm{~km}$, with an incline of $5604 \mathrm{~m}$ and a decline of $4356 \mathrm{~m}$. All subjects were fully informed of the procedure and gave their written consent to participate. For more detailed information on the methods, see the study registration information in the ClinicalTrails.gov database (registration number NCT03990259). 


\subsection{Study Population and Ethical Approval}

The sample was composed entirely of amateur runners. In total, 35 women finished the race. Our sample size included 18 female athletes, representing $51.42 \%$ of the total sample finishers. This sample can be considered representative, with a $95 \%$ confidence interval, a precision of $6 \%$, and a proportion of $3 \%$.

The mean age was $41+/-6$ years, with an average height of $1.61 \pm 0.05$ centimeters and weight of $56.92 \pm 4.36$ kilograms. In relation to training habits, the runners underwent $4.87 \pm 0.9$ days of weekly training, with an average training time of $9.07 \pm 2.54 \mathrm{~h}$ and distance of $73.07 \pm 43.32$ kilometers. The average length of menstrual bleeding was $3.56 \pm 1.04$ days, and a total of 6 participants in the study used some type of hormonal contraception ( 2 used oral contraceptives, 1 used a vaginal ring, and 3 used hormonal IUDs).

The investigation was conducted according to the Declaration of Helsinki, and the project was approved by the Research Ethics Committee of the university (file number $\mathrm{CD} / 007 / 2019)$. Informed consent was obtained from all subjects participating in the study.

\subsection{Hematological Variables}

Blood samples were collected from an antecubital vein by venipuncture on the same day of the race prior to starting, after crossing the finishing line, and 24 and $48 \mathrm{~h}$ later. The serum hormones related to the menstrual cycle used in the present investigation were estradiol and testosterone. Lactate dehydrogenase (LDH) and creatine kinase (CK) were used as indicators of muscle membrane disruption resulting from tissue injury. The hematological variables included ferritin, hemoglobin, hematocrit, and red blood cell count. The biochemical results obtained immediately post-race were adjusted by employing the Dill and Costill method [22], using hematocrit and hemoglobin to determine the magnitude of plasma volume changes after the race in each participant.

\subsection{Body Mass Index (BMI) and Body Composition Assessment}

Prior to starting on the same day as the race we measured the height and weight of all volunteers. They were also subjected to a body composition evaluation test (Tanita BC-780MA, Tanita Corp., Tokyo, Japan).

\subsection{Loss of Strength Measurement}

To assess the force, speed, and power of the extensor muscles in the lower extremities we used the squat-jump (SJ) test. The SJ test has been validated and is based on 3 simple parameters (body mass, jump height, and push distance) [23].

Grip strength (HG) is a direct measure of hand skeletal muscle strength. It is an index of endurance and general muscle capacity, and can reflect the association between peripheral strength and exercise capacity [24].

Previous studies have also suggested that the strength decline index (SDI), calculated as the decline in strength as a proportion of baseline values (measured through tests such as the HG and SJ), is a useful assessment of muscle fatigue [25].

Briefly, volunteers were first familiarized 3 to 5 times with the technical aspects of the testing procedures. The HG and SJ tests were performed before the race and $15 \mathrm{~min}$ after the race. For the HG assessment, volunteers remained in standing position, holding the grip dynamometer (T.K.K. 5401 GRIP-D, Takei Scientific Instruments Co., Tokyo, Japan) in their dominant hand. They were asked to squeeze the dynamometer for $5 \mathrm{~s}$ and the test was performed twice, with $30 \mathrm{~s}$ of rest in between attempts. The peak value for each individual was retained for statistical analysis.

For the SJ, the participants were asked to jump as high as possible. In the starting position, hips and knees were flexed $80^{\circ}$ and hands were immobilized on hips to avoid arm swing. Jump height was estimated by the flight time as measured with a contact platform (Chronojump, Barcelona, Spain). The test was performed twice, with $90 \mathrm{~s}$ of rest between attempts. Each individual's best performance value was retained for statistical analysis [26]. 


\subsection{Statistical Methods}

The level of significance was established at $p<0.05$. The data are presented as the mean \pm standard error of the mean (SEM). We opted for non-parametric analysis [27] due to the sample size $(n<30)$. Spearman's correlation analysis was used to assess whether the baseline values of sex hormones were interrelated or related to the loss of upper (HG) and lower limb (SJ) strength, hematological variables representing muscle membrane disruption (CK, $\mathrm{LDH})$, and the percentage of muscle mass (MM). For each subject, values for the variables HG, SJ, MM, CK, and LDH post-race and 24 and $48 \mathrm{~h}$ later were related to the individual baseline levels to define the delta scores $(\Delta): \Delta($ fold increase $)=($ post-race value-baseline value)/baseline value [28].

Test outcome meaningfulness was estimated through the size of the estimated effect of the correlation: strong, moderate, and small ( $>0.5,0.3-0.5$, and $<0.3$, respectively).

Regarding the use of $\mathrm{HC}$ method, the strength and muscular damage variables (expressed as a delta score of the baseline values for each subject) were compared using the Mann-Whitney U test. The test outcome meaningfulness was estimated through Cohen's $\mathrm{d}$ effect size pairwise comparisons. A Cohen's d value $<0.5$ was considered small, while a value between 0.5 and 0.8 was considered moderate, and a value greater than 0.8 was considered as large.

Finally, multiple regression analysis was performed using the forward stepwise method. Only normally distributed variables were used as dependent variables. Among the models obtained, the parsimony principle was applied [29]. Given the limited simple size and the non-normal distribution of independent variables, residual errors from the resulting models were inspected to ensure their normal distribution and, thus, the reliability of our regression models [30]. To identify the predictive value of the model, the Cohen criterion [31] was applied to one-way ANOVA models. This criterion indicates that $R^{2}$ values less than 0.10 do not present a relevant explanatory value, while $R^{2}$ values between 0.10 and 0.25 indicate a dependence of the explanation of the variance of the analyzed variable on the identified factors, and with $\mathrm{R}^{2}$ values above 0.25 , we can affirm that the explanatory model is very clinically relevant.

\section{Results}

The average race finish time was $22 \mathrm{~h} 20 \mathrm{~min} \pm 2 \mathrm{~h} 24 \mathrm{~min}$. Data regarding sex hormones and variables of muscle fatigue, systemic inflammation, and damage to muscle tissues are shown in Table 1. Repeated-measures analysis demonstrated significant differences in CK and LDH values pre-race as compared to immediately post-race and $24 / 48 \mathrm{~h}$ later. Similarly, significant differences were found between the loss of muscle strength measured with the HG, SJ, and loss of muscle mass after the ultramarathon. Baseline values of sex hormones, fatigue, and muscle strength were within the normal clinical range.

Table 1. Descriptive data on sex hormones and variables of muscle fatigue, loss of muscle mass, and injury to muscle tissues $($ mean $\pm \mathrm{SD})$.

\begin{tabular}{ccccc}
\hline & Baseline Data & Finish Line & 24 h Post-Race & 48 h Post-Race \\
\hline Estradiol $(\mathrm{pg} / \mathrm{mL})$ & $89.06 \pm 87.99$ & & & \\
Testosterone (ng/dL) & $19.34 \pm 9.34$ & & & \\
T/E ratio & $1.25 \pm 1.99$ & & & \\
CK (ui/L) & $137.59 \pm 54.73$ & $5075.76 \pm 3871.18^{*}$ & $2036.61 \pm 1389.83 * \#$ & $905.30 \pm 534.95 * \#$ \\
LDH (ui/L) & $185.88 \pm 25.29$ & $380.59 \pm 112.80 *$ & $320.93 \pm 93.97 * \#$ & $303.38 \pm 86.67 * \#$ \\
MM (\%) & $39.20 \pm 3.45$ & $38.00 \pm 4.86^{*}$ & & \\
HG (kg) & $31.33 \pm 3.69$ & $28.67 \pm 4.10^{*}$ & & \\
SJ (cm) & $20.76 \pm 2.72$ & $18.47 \pm 2.38^{*}$ & & \\
\hline
\end{tabular}

Abbreviations: T/E ratio: testosterone/estradiol ratio; CK: creatine kinase; LDH: lactate dehydrogenase; MM: muscle mass; HG: hand grip; SJ: squat jump. ${ }^{*}$ Significantly different from the preceding time point $(p<0.05)$; \# significantly different from the pre-race value $(p<0.05)$. 
Spearman's correlations between sex hormones, muscle fatigue variables, and indirect markers of muscle damage are listed in Table 2 . We analyzed the correlation coefficients to determine whether testosterone and estradiol were correlated with muscle fatigue variables and indirect markers of muscle damage. The correlation coefficients of muscle membrane disruption for $\Delta$ CK finish line, $\Delta$ CK $24 \mathrm{~h}, \Delta \mathrm{CK} 48 \mathrm{~h}, \Delta \mathrm{LDH} 24 \mathrm{~h}$, and $\Delta \mathrm{LDH} 48 \mathrm{~h}$ were $-0.674,-0.585,-0.619,-0.585$, and -0.615 , respectively, indicating a correlation with testosterone levels $(p<0.05)$. Moreover, a correlation was found between $\Delta \mathrm{HG}$ finish line and testosterone levels $(p<0.05)$, as shown in Figures 1 and 2. The correlation coefficient was -0.755 .

Table 2. Spearman correlations between sex hormones, muscle fatigue variables, and indirect markers of muscle damage.

\begin{tabular}{cccc}
\hline & $\begin{array}{c}\text { Estradiol } \\
\text { Correlation } \boldsymbol{r} \text { Value/ } \boldsymbol{p} \text { Value }\end{array}$ & $\begin{array}{c}\text { Testosterone } \\
\text { Correlation } \boldsymbol{r} \text { Value/ } \boldsymbol{p} \text { Value }\end{array}$ & $\begin{array}{c}\text { T/E Ratio } \\
\text { Correlation } \boldsymbol{r} \text { Value/ } \boldsymbol{p} \text { Value }\end{array}$ \\
\hline$\Delta$ CK finish line & $-0.199 / 0.514$ & $-0.674 * / 0.012$ & $0.435 / 0.137$ \\
$\Delta$ CK 24 h & $-0.324 / 0.280$ & $-0.652 * / 0.016$ & $0.319 / 0.288$ \\
$\Delta$ CK 48 h & $-0.428 / 0.145$ & $-0.619 * / 0.024$ & $0.134 / 0.662$ \\
$\Delta$ LDH finish line & $-0.065 / 0.832$ & $-0.541 / 0.056$ & $0.581^{*} / 0.037$ \\
$\Delta$ LDH 24 h & $-0.114 / 0.712$ & $-0.585 * / 0.036$ & $0.595 * / 0.032$ \\
$\Delta$ LDH 48 h & $-0.147 / 0.631$ & $-0.615 * / 0.025$ & $0.620^{*} / 0.024$ \\
$\Delta$ MM finish line & $0.202 / 0.508$ & $-0.466 / 0.109$ & $0.625^{*} / 0.02$ \\
$\Delta$ S finish line & $-0.206 / 0.520$ & $0.132 / 0.683$ & $-0.065 / 0.841$ \\
$\Delta$ HG finish line & $-0.472 / 0.104$ & $-0.755^{*} / 0.003$ & $-0.034 / 0.912$ \\
\hline
\end{tabular}

Abbreviations: $\Delta$ CK: fold increase creatine kinase; $\Delta$ LDH: fold increase lactate dehydrogenase; $\Delta \mathrm{MM}$ : fold increase muscle mass; $\Delta \mathrm{SJ}$ : fold increase squat jump; $\Delta$ HG: fold increase hand grip. ${ }^{*}$ Significantly different $(p<0.05)$.

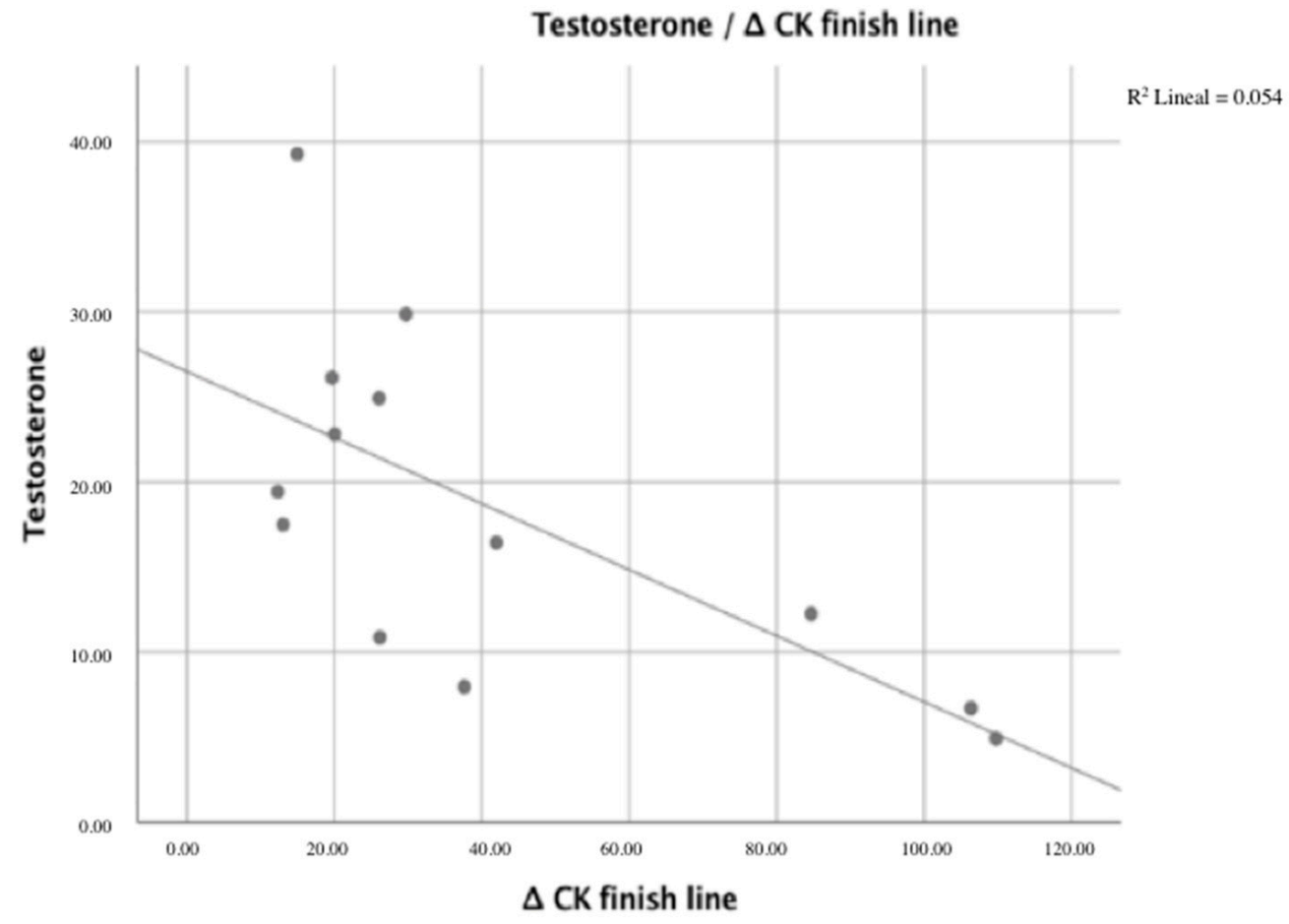

Figure 1. Correlation between $\Delta \mathrm{CK}$ finish line and testosterone levels.

Results of the testosterone/estrogen ratio demonstrated a correlation with $\mathrm{LDH}$ and loss of MM (Figure 3) for the following finish-line parameters: $\Delta \mathrm{LDH}$ finish line, $\Delta \mathrm{LDH}$ $24 \mathrm{~h}, \Delta \mathrm{LDH} 48 \mathrm{~h}$, and $\Delta \mathrm{MM}$ finish line $(p<0.05)$. The correlation coefficients values were $0.581,0.595,0.620$, and 0.625 , respectively. 


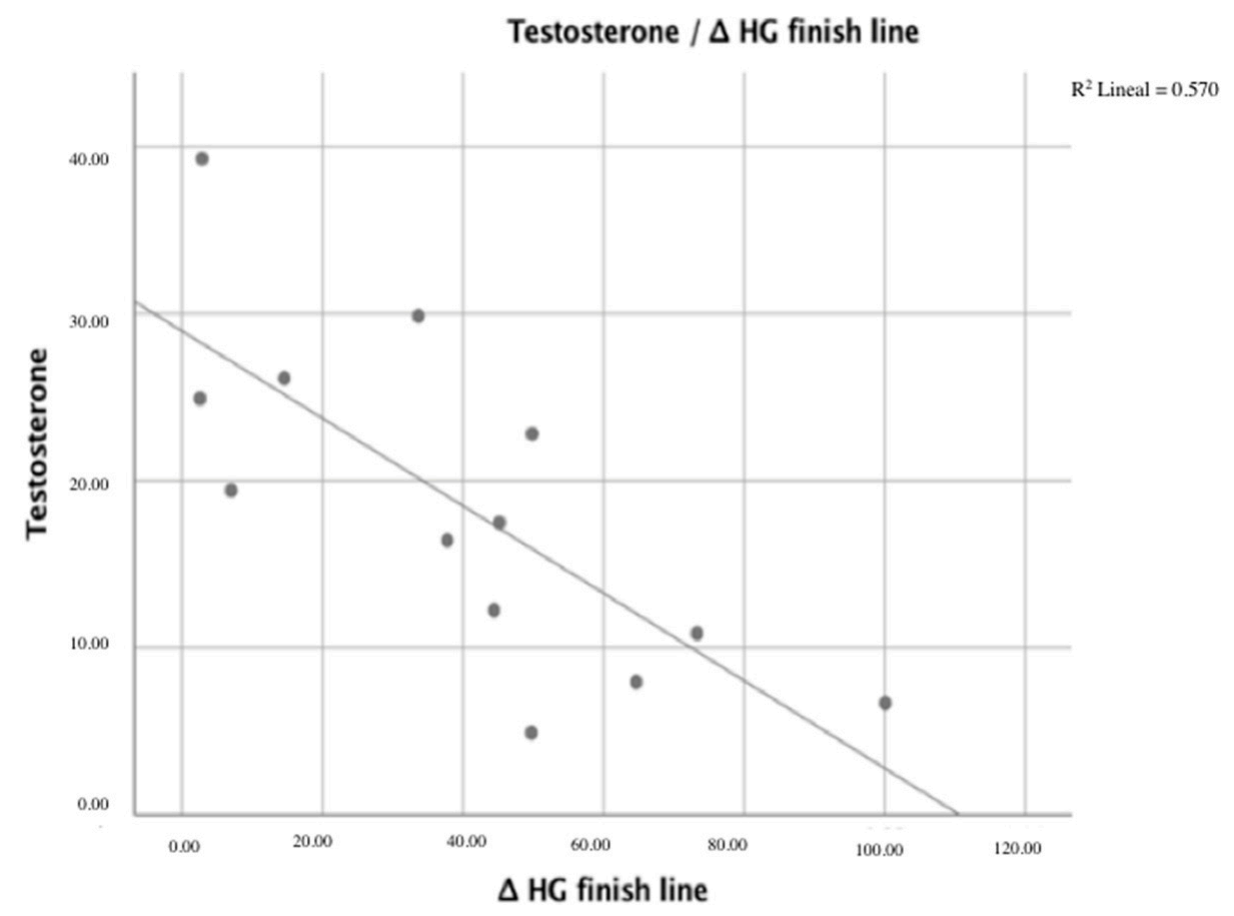

Figure 2. Correlation between $\Delta \mathrm{HG}$ finish line and testosterone levels.

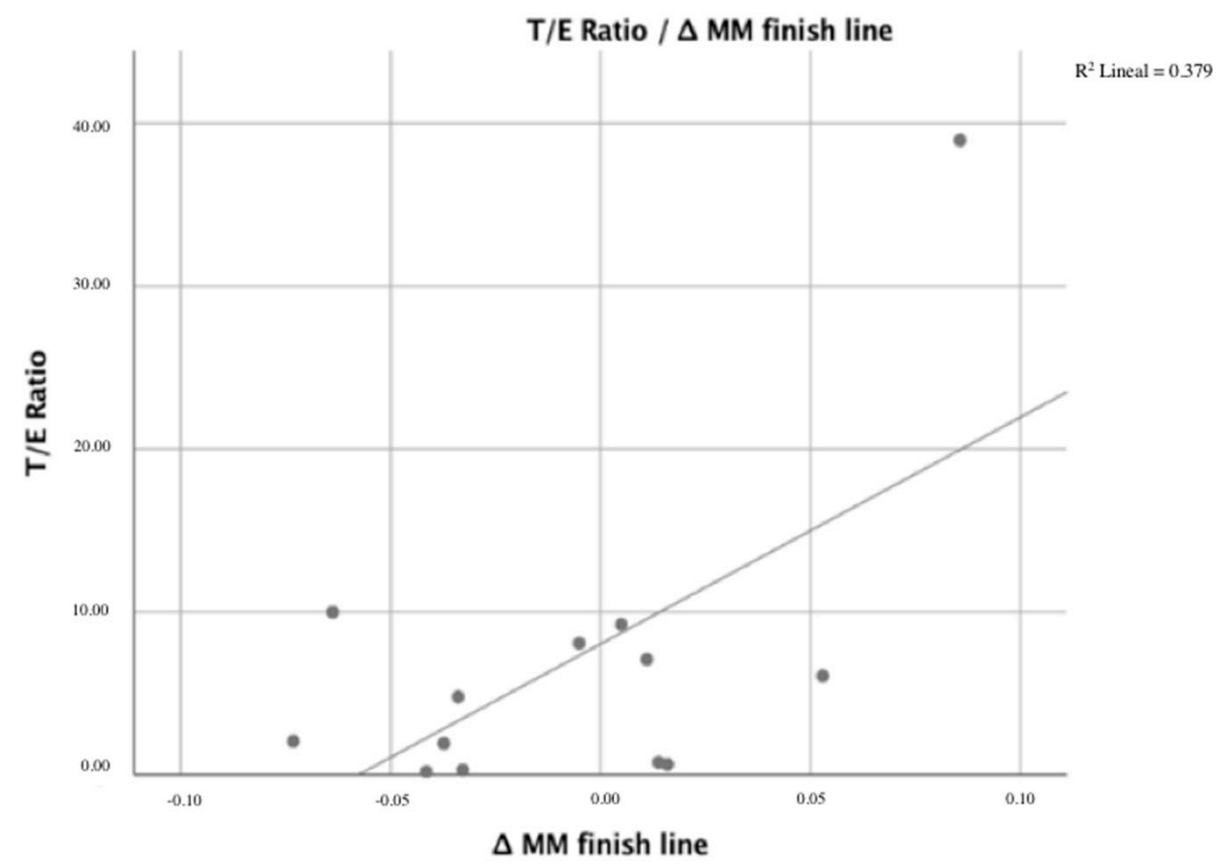

Figure 3. Correlation between $\Delta \mathrm{MM}$ finish line and $\mathrm{T} / \mathrm{E}$ ratio.

The relationship between HC groups and the study variables is shown in Table 3. An $\mathrm{HC}$ method was used by $30.76 \%$ of female runners. No significant differences were found between the groups in the study (Figure 4). Regarding the use of the HC method, estradiol levels differed statistically between HC and non-HC users (33.10-32.83 and 129.20-93.85; $p<0.05$, respectively). Interestingly, although the Mann-Whitney $U$ test did not show significant differences, a tendency was found between groups for all the serum concentration hematological parameters. 
Table 3. Relation between contraceptive groups and study variables.

\begin{tabular}{|c|c|c|c|}
\hline & $\begin{array}{c}\text { No Hormonal Contraceptive } \\
\text { Methods }\end{array}$ & $\begin{array}{l}\text { Hormonal Contraceptive } \\
\text { Methods }\end{array}$ & $p$-Value/d Cohen \\
\hline Baseline ferritin (ng/mL) & $24.11 \pm 11.37$ & $24.72 \pm 8.75$ & 0.912 \\
\hline Red blood cells (ng/mL) & $4.649 \pm 0.25$ & $4.90 \pm 0.29$ & 0.084 \\
\hline Hemoglobin (g/dL) & $14.24 \pm 1.31$ & $14.41 \pm 1.23$ & 0.792 \\
\hline Baseline red blood cells (\%) & $43.05 \pm 3.14$ & $43.78 \pm 2.91$ & 0.645 \\
\hline Estradiol $(\mathrm{pg} / \mathrm{mL})$ & $129.20 \pm 93.85$ & $33.10 \pm 32.83$ & $0.012 * / 2.16$ \\
\hline Testosterone (ng/dL) & $21.58 \pm 10.37$ & $16.79 \pm 7.57$ & 0.313 \\
\hline $\mathrm{T} / \mathrm{E}$ ratio & $0.86 \pm 1.78$ & $1.97 \pm 2.33$ & 0.290 \\
\hline CK (IU/L) baseline & $147.80 \pm 66.65$ & $126.83 \pm 31.012$ & 0.485 \\
\hline CK (IU/L) finish line & $5640.55 \pm 4572.41$ & $3072.91 \pm 940.02$ & 0.303 \\
\hline CK (IU/L) $24 \mathrm{~h}$ & $2202.62 \pm 1613.55$ & $1392.00 \pm 415.22$ & 0.356 \\
\hline CK (IU/L) $48 \mathrm{~h}$ & $921.25 \pm 563.60$ & $646.50 \pm 197.30$ & 0.246 \\
\hline LDH (IU/L) baseline & $187.50 \pm 31.28$ & $181.00 \pm 14.71$ & 0.643 \\
\hline LDH (IU/L) finish line & $393.36 \pm 132.56$ & $327 \pm 41.45$ & 0.366 \\
\hline LDH (IU/L) $24 \mathrm{~h}$ & $331.37 \pm 117.06$ & $290.75 \pm 37.50$ & 0.522 \\
\hline LDH (IU/L) $48 \mathrm{~h}$ & $309.62 \pm 110.85$ & $286.50 \pm 28.06$ & 0.696 \\
\hline MM (\%) baseline & $43.85 \pm 3.65$ & $45.26 \pm 3.16$ & 0.439 \\
\hline MM (\%) finish line & $43.36 \pm 5.12$ & $44.27 \pm 4.86$ & 0.439 \\
\hline$\Delta \mathrm{SJ}$ finish line & $-0.16 \pm 0.07$ & $-0.06 \pm 0.14$ & 0.112 \\
\hline$\Delta$ HG finish line & $-0.10 \pm 0,12$ & $-0.01 \pm / 0.10$ & 0.771 \\
\hline
\end{tabular}

Abbreviations: CK: creatine kinase; LDH: lactate dehydrogenase; MM: muscle mass; $\Delta$ SJ: fold increase squat jump; $\Delta$ HG: fold increase hand grip. * Significantly different $(p<0.05)$.

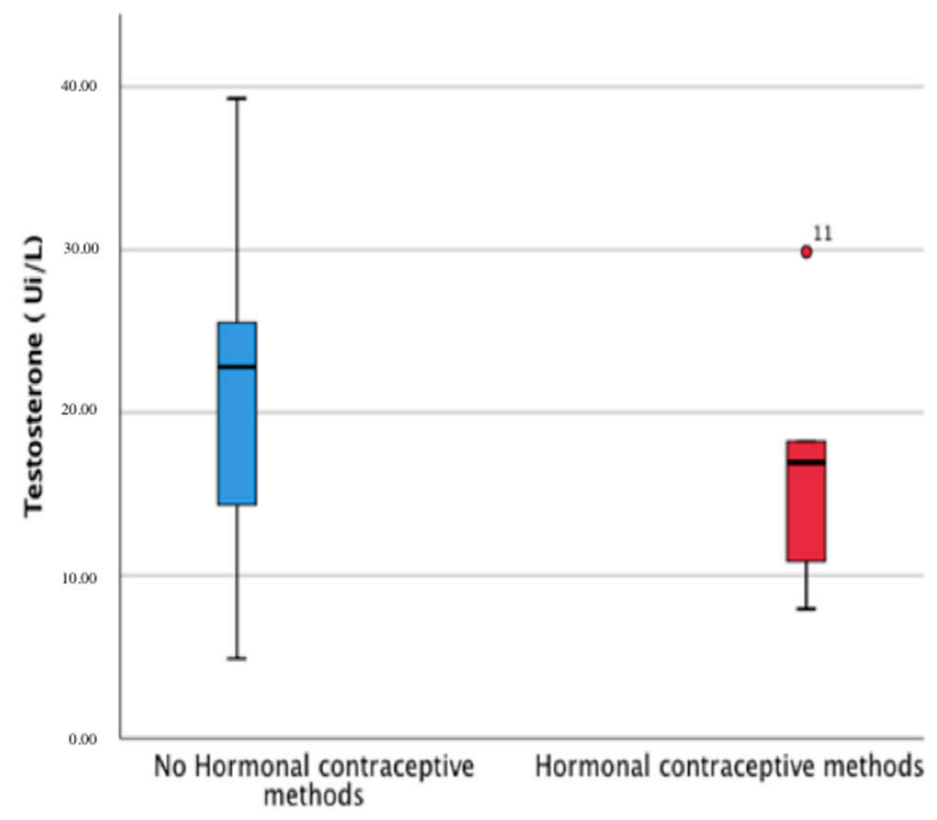

Figure 4. Testosterone levels (IU/L) in the non-HC and HC method groups.

Results from a multivariate analysis are shown in Table 4a,b. In these models, the dependent variables used for the regression equations were indicators of muscle fatigue, cell membrane disruption, and loss of muscle mass. The predictive variables were testosterone and the testosterone/estrogen ratio. We can consider that in our regression equations within a multicausal model, testosterone was the main protective factor against the muscle damage and fatigue caused by severe exhaustion after the ultramarathon. This observed phenomenon, as can be seen in Table 3 was more evident in women who were not receiving hormonal contraception. 
Table 4. Multivariate analysis.

\begin{tabular}{|c|c|c|c|c|}
\hline \multicolumn{5}{|c|}{ a. Linear regression models. } \\
\hline Model & $\mathbf{R}^{2}$ Adjusted & $\begin{array}{c}\text { Standardized } \\
\text { Coefficients Beta }\end{array}$ & Standard Error & $\mathbf{F}(p)$ \\
\hline $\begin{array}{c}\text { Dependent variable: } \Delta \text { CK finish line } \\
\text { Covariables: Testosterone. }\end{array}$ & 0.405 & -0.674 & 2.69663 & $9.151(0.012)$ \\
\hline $\begin{array}{c}\text { Dependent variable: } \Delta \text { LDH finish line } \\
\text { Covariables: } \mathrm{T} / \mathrm{E} \text { ratio. }\end{array}$ & 0.479 & -0.579 & 0.36986 & 6.507 (0.015) \\
\hline $\begin{array}{c}\text { Dependent variable: } \Delta \text { HG finish line } \\
\text { Covariables: Testosterone }\end{array}$ & 0.531 & -0.755 & 0.19891 & $14.567(0.003)$ \\
\hline $\begin{array}{c}\text { Dependent variable: } \Delta \mathrm{MM} \text { finish line } \\
\text { Covariables: } \mathrm{T} / \mathrm{E} \text { ratio. }\end{array}$ & 0.335 & 0.625 & 3.96370 & $7.056(0.022)$ \\
\hline \multicolumn{5}{|c|}{ b. Linear regression models for women not receiving hormonal contraception $(n=11 ; 66.7 \%)$. } \\
\hline Model & $\mathbf{R}^{2}$ Adjusted & $\begin{array}{c}\text { Standardized } \\
\text { Coefficients Beta }\end{array}$ & Standard Error & $\mathbf{F}(p)$ \\
\hline $\begin{array}{c}\text { Dependent Variable: } \Delta \text { CK finish line } \\
\text { Covariables: Testosterone. }\end{array}$ & 0.689 & -3.222 & 0.744 & $18.756(0.003)$ \\
\hline $\begin{array}{c}\text { Dependent Variable: } \Delta \text { LDH finish line } \\
\text { Covariables: Testosterone. }\end{array}$ & 0.702 & -0.046 & 0.31096 & 19.819 (0.003) \\
\hline $\begin{array}{c}\text { Dependent Variable: } \Delta \text { HG finish line } \\
\text { Covariables: Testosterone }\end{array}$ & 0.556 & -0.022 & 0.19891 & $8.777(0.021)$ \\
\hline $\begin{array}{c}\text { Dependent Variable: } \Delta \text { MM finish line } \\
\text { Covariables: T/E Ratio. }\end{array}$ & 0.658 & 0.370 & 2.9994 & $16.371(0.005)$ \\
\hline
\end{tabular}

Abbreviations: $\Delta \mathrm{CK}$ : fold increase creatine kinase; $\Delta \mathrm{LDH}$ : fold increase lactate dehydrogenase; $\mathrm{T} / \mathrm{E}$ ratio: testosterone/estrogen ratio; $\Delta$ HG: fold increase hand grip; $\Delta \mathrm{MM}$ : fold increase muscle mass).

\section{Discussion}

The results from the present study highlight testosterone levels as a predicting factor of loss of strength and muscle damage after ultra-endurance events in female athletes. Moreover, the $\mathrm{T} / \mathrm{E}$ ratio suggests a possible indirect role of estrogens in reducing exerciseinduced muscle damage and improving the recovery of athletes.

Menstrual cycle disturbances are common in women performing prolonged strenuous exercise at competitive levels. These disturbances have traditionally been considered to be secondary to energy deficiency and a suppressed hypothalamic pituitary-gonadal axis $[32,33]$. Amenorrhea, estrogen deficiency, and low energy availability are associated with a rapid loss of bone mass and an elevated risk of musculoskeletal injuries [34]. Moreover, under low energy availability, LH pulsatility is abolished and levels of testosterone are low [15]. However, not all female athletes who exhibit disturbances in their menstrual cycle present with this catabolic situation. In this respect, Hagmar [13] recently demonstrated that essential hyperandrogenism, such as that associated with PCOS, represents an alternative cause of menstrual disorders in athletes. Interestingly, the levels of testosterone in women diagnosed with PCOS are within the upper physiological limits. Furthermore, these athletes present an increased anabolic state, as they have more muscle mass and better bone mineral density as compared to other female athletes [35].

Testosterone is one of the most potent naturally secreted androgenic anabolic hormones. In muscle, it stimulates protein synthesis with an anabolic effect [36] and inhibits protein degradation with an anti-catabolic effect [37]. This leads to increased protein synthesis and decreased protein breakdown [38]. Traditionally, this compound has been abused by elite athletes to achieve these anabolic effects. In women, although testosterone is not generally considered to be a primary anabolic hormone, it nonetheless has a powerful effect on muscle tissue [38]. In fact, recently, Hirschberg et al. [14], in a double blind, randomized, placebo-controlled study, investigated the effects of moderately increased testosterone concentrations on physical performance in young women, finding that the supplemented group showed increased performance and muscle strength. 
Our study showed that the participants' basal testosterone levels were within the low range of normal testosterone concentrations. This finding is in accordance with previous published data regarding gender-specific differences in sex hormones as a result of ultra-endurance exercise $[39,40]$, and is better explained by the hypometabolic state hypothesis since this endocrine disturbance is characterized by low testosterone levels [4]. Moreover, in our results, participants with higher testosterone levels showed less strength loss and muscle membrane disruption after ultra-endurance exercise. This finding was supported by the strong negative correlations found between levels of this hormone; indirect markers of muscle damage, such as CK (at the finish line and 24/48 h later) and $\mathrm{LDH}$ (24/48 h later); and the evolution of the HG test before and after the ultra-trail race. These results were especially relevant for testosterone levels in the group not receiving exogenous hormone supplementation through HC. In this group, the variability explained by our models increased dramatically, indicating that levels of testosterone might be able to predict variability of $68.9 \%, 70.2 \%, 55.6 \%$, and $65.8 \%$ for CK, $\mathrm{LDH}, \mathrm{HG}$, and the MM delta value, respectively. In accordance with the criterion proposed by Cohen [31], our regression analysis within a multicausal model demonstrates that testosterone is the main protective factor against muscle damage and fatigue after severe exertion on running an ultramarathon.

In contrast, no effect of basal estrogen levels was observed. However, the T/E ratio positively correlated with the loss of muscle strength and the increase in muscle membrane disruption immediately after the race and $48 \mathrm{~h}$ later. These results suggest an indirect protective role of estrogens in female ultramarathon runners and mark the relevance of sex hormone interactions. In accordance with our proposed role of estrogens, Hansen [41] described a similar estrogen-elicited mechanism that increases sensitivity to training, reducing exercise-induced muscle damage and improving recovery. Regarding the $\mathrm{T} / \mathrm{E}$ ratio, some other authors have considered this relationship to be an over-training predictor associated with fatigue in male athletes $[17,18]$. To date, there is no previous literature regarding this ratio in female athletes, however, in our study, the participants showed a much lower ratio than male athletes. This was an expected result since estrogen is the primary female sex hormone. Further investigation is necessary to confirm this novel result in female runners and its physiological implications in ultra-endurance sports performance.

Regarding the use of HC methods, in our study, we did not find differences between women who used contraceptives and those who did not in relation to strength and muscle damage after ultra-endurance exercise, indicating that no added benefit is provided by adjusting the menstrual cycle with HC. As expected, estrogen levels were significantly decreased in this group because of HPA downregulation. However, further studies are necessary to confirm the effect of different types of HC upon HPA axis inhibition in ultratrail runners. We did not find differences in baseline hematological variables and serum iron levels in our study groups. In line with this, it has been reported that resistance and exercise performance are not affected by changes in the menstrual cycle resulting from the use of contraceptives [42-45]. However, other authors have highlighted the possible benefit of HC methods for reducing menstrual blood loss and increasing serum iron levels, which may contribute to a greater oxygen-carrying capacity [46].

\section{Limitations}

This study yielded important results on the role of testosterone in muscle physiology in female athletes. However, it has some limitations. The first is in regards to the HC type, dose, and route of administration. Although functionally these contraceptives target anovulation, their effects on the HPA axis differ. Secondly, it is extremely difficult to obtain large samples of women participating in 115-kilometer races. In this context, having achieved a sample of $n=19$ female athletes is notable. However, it would be desirable to expand the number of similar studies to obtain larger and more representative samples and contrast the results. Finally, there is the impossibility of obtaining volunteer participants at 
the same point in their menstrual cycle. These difficulties condition the methodological design of the study.

\section{Conclusions}

Even though the current literature suggests that fluctuations in female steroid hormones throughout the menstrual cycle do not affect muscle strength, in our research, we found a relationship between these variables and endogenous serological basal testosterone serum levels.

The T/E ratio may be a good predictor of muscle damage and post-race recovery, but this needs to be studied in greater detail in future investigations.

We did not find differences between $\mathrm{HC}$ users and non-HC users in terms of hematological variables, strength, systemic inflammation, or muscle damage after running an ultra-trail race.

A practical implication of these findings would be that in female athletes participating in specific endurance sports, such as ultra-trail racing, it is not necessary to adjust the menstrual cycle using HC to maximize competitive capacity, as this provides no added benefit.

However, depending on the menstrual cycle phase, there are physiological fluctuations in endogenous testosterone levels that condition greater fatigability and muscle damage after training. This factor could be taken into consideration in the design of training guidelines. Moreover, the present findings could provide a basis for a new approach to improve recovery patterns after ultra-long-distance events depending on the menstrual cycle phase.

Author Contributions: Conceptualization, E.C.-B., C.H. and A.B.-R.; methodology, C.H. and B.H. validation, E.C.-B., C.H. and M.M.; formal analysis, E.C.-B., M.M., P.B. and C.H.; investigation, P.R.-P. and I.M.-N.; resources, C.H.; data curation, E.C.-B. and P.B.; writing-original draft preparation, A.B.R., P.B., M.M. and E.C.-B. writing-review and editing, M.M., P.B. and E.C.-B.; project administration, C.H. and I.M.-N.; funding acquisition, C.H. All authors have read and agreed to the published version of the manuscript.

Funding: This research was funded by the Vithas Hospitals group (https: / /vithas.es), the Penyagolosa Trails organization (http://penyagolosatrails.com), Catedra Endavant Villarreal CF de l'Esport (https://endavant.villarrealcf.es/), and the grant code UJI-B2019-38. The funders had no role in study design, data collection and analysis, the decision to publish, or preparation of the manuscript.

Institutional Review Board Statement: The investigation was conducted in accordance with the Declaration of Helsinki and approval for the project was obtained from the Research Ethics Committee of the University Jaume I of Castellon (File Number CD/007/2019). This study is enrolled in the ClinicalTrails.gov database with code number NCT03990259 (www.clinicaltrials.gov).

Informed Consent Statement: Informed consent was obtained from all subjects involved in the study.

Data Availability Statement: All data generated or analyzed during this study are included in this published article.

Acknowledgments: Fundación Trinidad Alfonso, the Vithas-Nisa Hospitals group, and Penyagolosa Trails HG. The authors are also grateful to all the staff involved in the organization of the Penyagolosa Trail 2019 and all ultra-trail runners and volunteers who participated in this study.

Conflicts of Interest: The authors declare no conflict of interest.

\section{References}

1. The State of Running 2019 | RunRepeat. Available online: https://runrepeat.com/state-of-running (accessed on 4 September 2021).

2. Stöhr, A.; Nikolaidis, P.T.; Villiger, E.; Sousa, C.V.; Scheer, V.; Hill, L.; Knechtle, B. An analysis of participation and performance of 2067 100-km ultra-marathons worldwide. Int. J. Environ. Res. Public Health 2021, 18, 362. [CrossRef]

3. Handelsman, D.J.; Hirschberg, A.L.; Bermon, S. Circulating testosterone as the hormonal basis of sex differences in athletic performance. Endocr. Rev. 2018, 39, 803-829. [CrossRef]

4. Hirschberg, A.L. Female hyperandrogenism and elite sport. Endocr. Connect. 2020, 9, R81-R92. [CrossRef] [PubMed] 
5. Notelovitz, M. Androgen effects on bone and muscle. Fertil. Steril. 2002, 77, 34-41. [CrossRef]

6. Herbst, K.L.; Bhasin, S. Testosterone action on skeletal muscle. Curr. Opin. Clin. Nutr. Metab. Care 2004, 7, 271-277. [CrossRef] [PubMed]

7. Hartgens, F.; Kuipers, H. Effects of androgenic-anabolic steroids in athletes. Sports Med. 2004, 34, 513-554. [CrossRef]

8. Stone, M.H.; Cardinale, M.; Stone, M.H. Is Testosterone Influencing Explosive Performance? Artic. J. Strength Cond. Res. 2006, 20, 103-107. [CrossRef]

9. Costello, J.T.; Bieuzen, F.; Bleakley, C.M. Where are all the female participants in Sports and Exercise Medicine research? Eur. J. Sport Sci. 2014, 14, 847-851. [CrossRef]

10. De Jonge, X.A.K.J. Effects of the menstrual cycle on exercise performance. Sports Med. 2003, 33, 833-851. [CrossRef]

11. Schaumberg, M.A.; Jenkins, D.G.; Janse de Jonge, X.A.K.; Emmerton, L.M.; Skinner, T.L. Three-step method for menstrual and oral contraceptive cycle verification. J. Sci. Med. Sport 2017, 20, 965-969. [CrossRef]

12. Scheid, J.; De Souza, M.J. Menstrual Irregularities and Energy Deficiency in Physically Active Women: The Role of Ghrelin, PYY and Adipocytokines. Cytokines Growth Mediat. Phys. Act. 2015, 55, 82-102. [CrossRef]

13. Hagmar, M.; Berglund, B.; Brismar, K.; Hirschberg, A.L. Hyperandrogenism May Explain Reproductive Dysfunction in Olympic Athletes. Med. Sci. Sports Exerc. 2009, 41, 1241-1248. [CrossRef]

14. Hirschberg, A.L.; Elings Knutsson, J.; Helge, T.; Godhe, M.; Ekblom, M.; Bermon, S.; Ekblom, B. Effects of moderately increased testosterone concentration on physical performance in young women: A double blind, randomised, placebo controlled study. Br. J. Sports Med. 2019. [CrossRef]

15. Rickenlund, A.; Thorén, M.; Carlström, K.; von Schoultz, B.; Hirschberg, A.L. Diurnal Profiles of Testosterone and Pituitary Hormones Suggest Different Mechanisms for Menstrual Disturbances in Endurance Athletes. J. Clin. Endocrinol. Metab. 2004, 89, 702-707. [CrossRef]

16. Bell, D.R.; Blackburn, J.T.; Norcorss, M.F.; Ondrak, K.S.; Hudson, J.D.; Hackney, A.C.; Padua, D.A. Estrogen and muscle stiffness have a negative relationship in females. Knee Surg. Sports Traumatol. Arthrosc. 2012, 20, 361-367. [CrossRef] [PubMed]

17. Cadegiani, F.A.; Kater, C.E. Basal hormones and biochemical markers as predictors of overtraining syndrome in Male athletes: The EROS-Basal study. J. Athl. Train. 2019, 54, 906-914. [CrossRef]

18. Martin, D.; Sale, C.; Cooper, S.B.; Elliott-Sale, K.J. Period prevalence and perceived side effects of hormonal contraceptive use and the menstrual cycle in elite athletes. Int. J. Sports Physiol. Perform. 2018, 13, 926-932. [CrossRef] [PubMed]

19. Larsen, B.; Morris, K.; Quinn, K.; Osborne, M.; Minahan, C. Practice does not make perfect: A brief view of athletes' knowledge on the menstrual cycle and oral contraceptives. J. Sci. Med. Sport 2020, 23, 690-694. [CrossRef]

20. Cheng, J.; Santiago, K.A.; Abutalib, Z.; Temme, K.E.; Hulme, A.; Goolsby, M.A.; Esopenko, C.L.; Casey, E.K. Menstrual Irregularity, Hormonal Contraceptive Use, and Bone Stress Injuries in Collegiate Female Athletes in the United States. PMER 2020. [CrossRef]

21. Oxfeldt, M.; Dalgaard, L.B.; Jørgensen, A.A.; Hansen, M. Hormonal contraceptive use, menstrual dysfunctions, and self-reported side effects in elite athletes in Denmark. Int. J. Sports Physiol. Perform. 2020, 15, 1377-1384. [CrossRef]

22. Dill, D.B.; Costill, D.L. Calculation of percentage changes in volumes of blood, plasma, and red cells in dehydration. J. Appl. Physiol. 1974, 37, 247-248. [CrossRef]

23. Martínez-Navarro, I.; Sánchez-Gómez, J.M.; Collado-Boira, E.J.; Hernando, B.; Panizo, N.; Hernando, C. Cardiac Damage Biomarkers and Heart Rate Variability Following a 118-Km Mountain Race: Relationship with Performance and Recovery. $J$. Sports Sci. Med. 2019, 18, 615.

24. Dourado, V.Z.; de Oliveira Antunes, L.C.; Tanni, S.E.; de Paiva, S.A.R.; Padovani, C.R.; Godoy, I. Relationship of Upper-Limb and Thoracic Muscle Strength to 6-min Walk Distance in COPD Patients. Chest 2006, 129, 551-557. [CrossRef]

25. Reuter, S.E.; Massy-Westropp, N.; Evans, A.M. Reliability and validity of indices of hand-grip strength and endurance. Aust. Occup. Ther. J. 2011, 58, 82-87. [CrossRef]

26. Martínez-Navarro, I.; Sanchez-Gómez, J.M.; Aparicio, I.; Priego-Quesada, J.I.; Pérez-Soriano, P.; Collado, E.; Hernando, B.; Hernando, C. Effect of mountain ultramarathon distance competition on biochemical variables, respiratory and lower-limb fatigue. PLoS ONE 2020, 15, e0238846. [CrossRef]

27. Luckey, D.W. Nonparametric Statistics for Health Care Research: Statistics for Small Samples and Unusual Distributions. J. Am. Stat. Assoc. 1998, 93, 409-411. [CrossRef]

28. Guerrero, C.; Collado-Boira, E.; Martinez-Navarro, I.; Hernando, B.; Hernando, C.; Balino, P.; Muriach, M. Impact of Plasma Oxidative Stress Markers on Post-race Recovery in Ultramarathon Runners: A Sex and Age Perspective Overview. Antioxidants 2021, 10, 355. [CrossRef]

29. Stoica, P.; Söderström, T. On the parsimony principle. Int. J. Control 1982, 36, 409-418. [CrossRef]

30. Williams, M.N.; Grajales, C.A.G.; Kurkiewicz, D. Assumptions of multiple regression: Correcting two misconceptions. Pract. Assess. Res. Eval. 2013, 18, 1-14. [CrossRef]

31. Cohen, J. The analysis of variance and covariance. Stat. Power Anal. Behav. Sci. 1988, 88, 728.

32. Koltun, K.J.; Williams, N.I.; Scheid, J.L.; De Souza, M.J. Discriminating hypothalamic oligomenorrhea/amenorrhea from hyperandrogenic oligomenorrhea/amenorrhea in exercising women. Appl. Physiol. Nutr. Metab. 2020, 45, 707-714. [CrossRef] [PubMed]

33. Arena, B.; Maffulli, N.; Maffulli, F.; Morleo, M.A. Reproductive Hormones and Menstrual Changes with Exercise in Female Athletes. Sports Med. 1995, 19, 278-287. [CrossRef] [PubMed] 
34. Rickenlund, A.; Carlström, K.; Ekblom, B.; Brismar, T.B.; von Schoultz, B.; Hirschberg, A.L. Effects of Oral Contraceptives on Body Composition and Physical Performance in Female Athletes. J. Clin. Endocrinol. Metab. 2004, 89, 4364-4370. [CrossRef]

35. Rickenlund, A.; Carlström, K.; Ekblom, B.; Brismar, T.B.; Von Schoultz, B.; Hirschberg, A.L. Hyperandrogenicity is an alternative mechanism underlying oligomenorrhea or amenorrhea in female athletes and may improve physical performance. Fertil. Steril. 2003, 79, 947-955. [CrossRef]

36. Mauras, N.; Hayes, V.; Welch, S.; Rini, A.; Helgeson, K.; Dokler, M.; Veldhuis, J.D.; Urban, R.J. Testosterone deficiency in young men: Marked alterations in whole body protein kinetics, strength, and adiposity. J. Clin. Endocrinol. Metab. 1998, 83, 1886-1892. [CrossRef]

37. Demling, R.H.; Orgill, D.P. The anticatabolic and wound healing effects of the testosterone analog oxandrolone after severe burn injury. J. Crit. Care 2000, 15, 12-17. [CrossRef]

38. Vingren, J.L.; Kraemer, W.J.; Ratamess, N.A.; Anderson, J.M.; Volek, J.S.; Maresh, C.M. Testosterone physiology in resistance exercise and training: The up-stream regulatory elements. Sports Med. 2010, 40, 1037-1053. [CrossRef] [PubMed]

39. Berg, U.; Enqvist, J.K.; Mattsson, C.M.; Carlsson-Skwirut, C.; Sundberg, C.J.; Ekblom, B.; Bang, P. Lack of sex differences in the IGF-IGFBP response to ultra endurance exercise. Scand. J. Med. Sci. Sports 2008, 18, 706-714. [CrossRef]

40. Ginsburg, G.S.; O’Toole, M.; Rimm, E.; Douglas, P.S.; Rifai, N. Gender differences in exercise-induced changes in sex hormone levels and lipid peroxidation in athletes participating in the Hawaii Ironman triathlon: Ginsburg-gender and exercise-induced lipid peroxidation. Clin. Chim. Acta 2001, 305, 131-139. [CrossRef]

41. Hansen, M. Female hormones: Do they influence muscle and tendon protein metabolism? Proc. Nutr. Soc. 2018, 77, 32-41. [CrossRef]

42. Rechichi, C.; Dawson, B.; Goodman, C. Athletic performance and the oral contraceptive. Int. J. Sports Physiol. Perform. 2009, 4, 151-162. [CrossRef]

43. Rechichi, C.; Dawson, B.; Goodman, C. Oral Contraceptive Phase Has no Effect on Endurance Test. Int. J. Sports Med. 2008, 29, 277-281. [CrossRef] [PubMed]

44. Vaiksaar, S.; Jürimäe, J.; Mäestu, J.; Purge, P.; Kalytka, S.; Shakhlina, L.; Jürimäe, T. No Effect of Menstrual Cycle Phase and Oral Contraceptive Use on Endurance Performance in Rowers. J. Strength Cond. Res. 2011, 25, 1571-1578. [CrossRef] [PubMed]

45. Lebrun, C.M.; Joyce, S.M.; Constantini, N.W. Effects of Female Reproductive Hormones on Sports Performance. In Contemporary Endocrinology; Humana Press Inc.: Totowa, NJ, USA, 2020; pp. 267-301.

46. Keller, M.F.; Harrison, M.L.; Lalande, S. Impact of Menstrual Blood Loss and Oral Contraceptive Use on Oxygen-carrying Capacity. Med. Sci. Sports Exerc. 2020, 52, 1414-1419. [CrossRef] [PubMed] 